\title{
Espigando el tiempo: Agnès Varda y Walter Benjamin en busca de la vida cotidiana
}

\section{Artículo de investigación}

\section{Noraedén Mora Méndez}

University of Southern California, Los Angeles, USA moramend@usc.edu

Recibido: 2 de septiembre de 2019

Aprobado: 10 de octubre de 2019

Cómo citar este artículo: Mora Méndez, Noraedén (2020). Espigando el tiempo: Agnès Varda y Walter Benjamin en busca de la vida cotidiana. Calle 14: revista de investigación en el campo del arte 15(28).

pp. 238-251. https://doi.org/10.14483/21450706.16259

\section{(2) (1)}

https://creativecommons.org/licenses/by/4.0/deed.es 


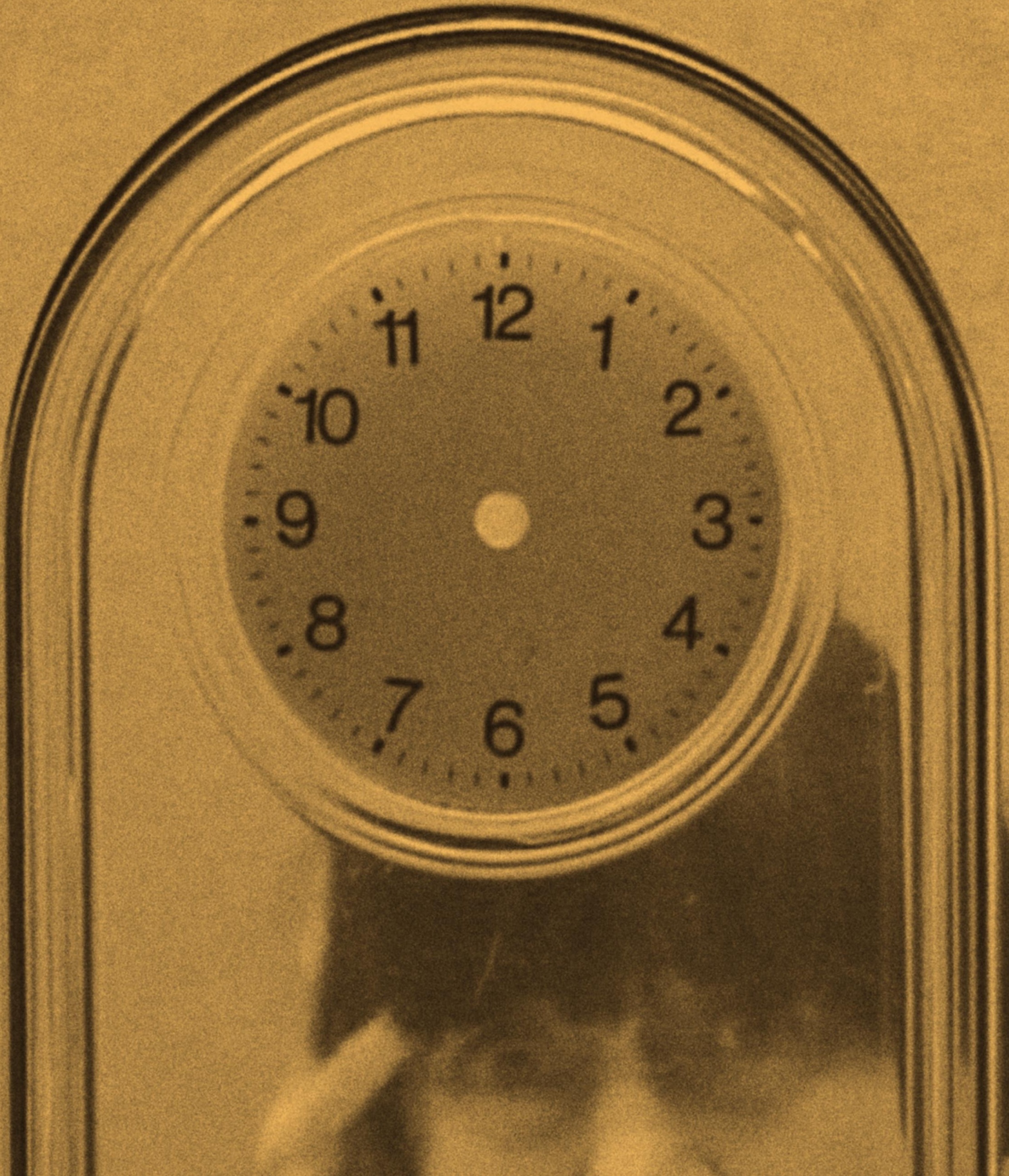




\begin{abstract}
Resumen
Los espigadores y la espigadora (2000), el documental de Agnès Varda, empieza reflexionando sobre el famoso cuadro de Millet del siglo XIX y el oficio de espigar. Recoger la cosecha en esas épocas contrasta con la labor de los espigadores de hoy que deben sobrevivir con lo que consigan en la calle. Este montaje de la vida cotidiana en dos tiempos y la experiencia misma de la cineasta permite entablar un diálogo con el trabajo de Walter Benjamin sobre la cotidianidad. Benjamin escribe sobre autores del siglo XIX y la experiencia de pérdida o shock en la modernidad y el rol de la memoria ante esta pérdida. En este sentido los conceptos de experiencia y tiempo están implicados en la memoria y la historia de la vida cotidiana. Varda y Benjamin, dialogando también con otros teóricos, buscan una vida cotidiana en un tiempo que difícilmente es progresivo.
\end{abstract}

\title{
Palabras clave
}

Experiencia; historia, memoria; tiempo; vida cotidiana.

\section{Gleaning Time: Agnès Varda and Walter Benjamin in Search of Everyday Life}

\begin{abstract}
The Gleaners and I (2000), Agnès Varda's documentary, begins by reflecting on Millet's famous painting from the 19th century and the labor of gleaning. Harvesting in those times is in contrast with the work of the gleaners of today, who must survive with what they can gather on the streets. This montage of daily life in two eras and the filmmaker's own experience allows a dialogue to be established with Walter Benjamin's work about everyday life. Benjamin writes about 19th century authors and the experience of loss or shock in modernity, and the role of memory in the face of this loss. In this sense, the concepts of experience and time are involved in the memory and history of everyday life. Varda and Benjamin, also in dialogue with other thinkers, seek an everyday life in a time that is hardly progressive.
\end{abstract}

\section{Keywords}

Experience; history; memory; time; everyday life.

Glaner le temps : Agnès Varda et Walter Benjamin à la recherche de la vie quotidienne

\section{Résumé}

Les glaneurs et la glaneuse (2000), le documentaire d'Agnès Varda, commence par une réflexion sur le célèbre tableau de Millet du XIXe siècle et le métier de glaneur. La récolte à cette époque contraste avec le travail des glaneurs d'aujourd'hui, qui doivent survivre avec ce qu'ils peuvent obtenir dans la rue. Ce montage de la vie quotidienne en deux époques et de la propre expérience du cinéaste permet d'établir un dialogue avec l'œuvre de Walter Benjamin sur la vie quotidienne. Benjamin écrit sur les auteurs du XIXe siècle et sur l'expérience de la perte ou du choc dans la modernité, aussi bien que sur le rôle de la mémoire face à cette perte. En ce sens, les concepts d'expérience et de temps sont impliqués dans la mémoire et l'histoire de la vie quotidienne. Varda et Benjamin, également en dialogue avec d'autres penseurs, recherchent une vie quotidienne à une époque peu progressiste.

\section{Mots clés}

Expérience ; I'histoire ; mémoire ; temps ; vie quotidienne. 
Os catadores e eu (2000), documentário de Agnès Varda, começa refletindo sobre o famoso quadro de Millet do século XIX e o oficio de respigar. A colheita nessas épocas contrasta com o labor dos respigadores de hoje que devem sobreviver com o que conseguem na rua. Esta montagem da vida cotidiana em dois momentos e a própria experiência da cineasta permitem entrar em diálogo com o trabalho de Walter Benjamin sobre a cotidianidade. Benjamin escreve sobre autores do século XIX e a experiência de perda ou shock na modernidade e o papel da memória diante desta perda. Neste sentido os conceitos de experiência e tempo estão implicados na memória e a história da vida cotidiana. Ambos, Varda e Benjamin, dialogando também com outros teóricos, buscam uma vida cotidiana em um tempo que dificilmente é progressivo.

\section{Palavras chave}

Experiência; história; memória; tempo; vida cotidiana.

Katichispa Kausaita Kai Iska runa Agnesvarday Benjamin Sutikuna kawangapa Imasami kausanchi puncha puncha

\section{Maillallachiska}

Kai iska runanakuna munainakumi iuachinga imasami ñugpata iachaskakuna chagrapi ruralkuna apachinga sug runa kawaspa llapa llakiwa niku manima llugpasina kawari iuiachiku imasami llukanchi mana chingachinga nukanchi nukaska mana manchaspalla kausasunchi ñugpasinama katichisunchi sumaglla kawanakuspa aiachi sugkunawa kangapa.

\section{Rimangapa Ministidukuna}

Kausaska; ñugpamanda; iuiarispa; kausai-kunaura; puncha kausai. 
Ir a recoger papas defectuosas, esperar la cosecha de uvas de vino, ir a comprar pan, leer, escribir, hacer una película; todas son posibles escenas de alguna vida cotidiana. Lo cotidiano pareciera estar en medio de todas las cosas, abarcando innumerables temas $y$, al mismo tiempo, ninguno en concreto. Su estudio permite una variedad de preguntas básicas: qué, cómo, dónde y cuándo ocurre la vida cotidiana. Guy Debord intenta responder a estas preguntas proponiendo algo a lo que regresaremos más adelante: "es la medida de todas las cosas" (1999, p. 188); lo que nos sigue ofreciendo una respuesta demasiado amplia o incierta acerca de qué es o qué podría ocurrir en la vida cotidiana. Quizás uno de los elementos más importantes en el que han estado de acuerdo la mayoría de los teóricos de la vida cotidiana es precisamente su dimensión temporal; por ejemplo, Peter Osborne (1992) sostendría que el estudio de la vida cotidiana halla su sentido precisamente en su forma temporal. La vida cotidiana podría tomarse como ese espacio en el que se relacionan el presente y el pasado. Será justamente a este aspecto temporal al que nos intentaremos aproximar y recorrer en el presente ensayo. Así, a través de la yuxtaposición de textos de distintas épocas y distintos medios como lo son los escritos de Walter Benjamin y el trabajo visual de Agnès Varda, nos acercaremos a la pregunta por la vida cotidiana, su relación con lo histórico y su naturaleza temporal.

\section{Las espigadoras}

El cuadro impresionista del siglo XIX de Jean-François Millet Des glaneuses (1857) (Las espigadoras) muestra un paisaje amarillento donde aparecen tres trabajadoras del campo recogiendo la cosecha (Imagen 1). Al fondo se ven montones de espigas ya agrupadas y alguna edificación que muestra una escena de vida campesina. Las espigadoras, esas mujeres dobladas hacia adelante con un brazo atajando ramilletes, también sirvieron de inspiración para la película de Agnès Varda, Les glaneurs et la glaneuse (Los espigadores y la espigadora) (2000). La directora comienza a narrarnos sus impresiones de este cuadro para luego llevarnos, de una manera casi violenta, a la práctica de 'espigar' hoy en día (Imagen 2).

Así, en un mismo montaje aparece la historia personal de la cineasta combinada con las narrativas cotidianas de personas que habitan en campos y ciudades; muchos de los personajes viven al margen del flujo maquinal de la vida moderna. Varda juega con los

diferentes posibles significados de la palabra espigar; por un lado, su sentido tradicional de recoger la cosecha, y por otro, una metáfora de la búsqueda; en ambos sentidos ella se considera una espigadora. A lo largo de un viaje de carretera va recopilando historias antiguas y actuales acerca del oficio de espigar, de la sobrevivencia en las ciudades, del arte, del cambio de épocas, del amor, también de sus recuerdos y el cambio de su propio cuerpo. Sus manos suelen aparecer en una especie de tematización de sus arrugas. Los ciclos y las repeticiones se ven como parte crucial del oficio de los espigadores, la espera de la cosecha o el mejor momento para los hallazgos. En este montaje Varda colecciona sus propios tesoros cotidianos: pinturas, objetos materiales, memorias e historias. 


\section{Vida cotidiana, trauma y lo extraordinario}

Antes de acercarnos más al filme de Varda y su relación con la vida cotidiana podemos dar un paso atrás para dialogar con el texto de Walter Benjamin (2008b) de 1939 sobre Charles Baudelaire y la modernidad. Benjamin ve en la poesía de Baudelaire una gran multitud que se mueve independientemente, como si tuviese alma propia. Un alma que Benjamin va a identificar también en otros autores y que va a explicar a través de conceptos históricos y temporales; así como una multitud no muy distinta a la que sigue encontrado Varda años después. Para Benjamin en Baudelaire, el alma es aquello que le da un aire enajenante a la ciudad y la muchedumbre. En estos poemas según Benjamin hay una suerte de tristeza de sentir extrañeza de lo más cotidiano: la ciudad y su gente. Esa multitud de la que habla Baudelaire resulta aterradora para el flâneur que empieza a dejar de sentir el brillo o el entusiasmo de estar en la ciudad. Benjamin (2008b) descubre el horror y el miedo como las principales emociones que rodean la ciudad descrita en el poema de Baudelaire (2014) "Extravío de aureola". El poema en prosa trata sobre un poeta que ha perdido su aureola cuando estaba tratando de atravesar un boulevard lleno de gente; el poeta, perdido en medio de la multitud, decide quedarse sin aureola a pesar de ser la insignia que lo identifica como poeta (Baudelaire, 2014). Según Benjamin (2008b), esa aureola es sometida a una experiencia o vivencia de shock, a un trauma. El trauma de la modernidad que implica la desintegración de su brillo o aura, $y$, justamente, para Benjamin esa es la experiencia de la vida cotidiana en la ciudad moderna.

En el documental de Varda la ciudad aparece como un espacio en cierta forma fallido, donde algunos de sus habitantes están constantemente tratando de encontrar alimentos y objetos para sobrevivir mientras las dinámicas cotidianas establecidas siglos atrás siguen transcurriendo. Hay un contraste que sugiere una especie de ruptura o shock entre la pintura de Millet -que muestra la tradicional vida campesina del siglo XIX-y la práctica urbana o rural de recolectar de hoy en día. Al contraponer los espigadores tradicionales con los espigadores de hoy, Varda se refiere a los segundos para decir "lo que me impresiona, es que cada uno espiga solitariamente" (Varda, 2000), mientras que en el cuadro de Millet las espigadoras trabajan en grupo, presumiblemente en familia. Varda muestra una ciudad mecanizada donde no existe una solución efectiva para aquellos que viven en los márgenes del sistema. Los personajes de este documental se resisten a las dinámicas que les son impuestas en las ciudades que habitan, pero, al Varda poner en evidencia que esta condición también los mantiene fuera de los intereses de la sociedad, nos recuerda la experiencia del poeta de Baudelaire que extravía su aureola y, con ella, la posibilidad de distinguirse de la multitud. El filme se acerca a personas que forman parte de una muchedumbre que difícilmente puede responder a la heterogeneidad de quienes la componen. Pero la manera de acercarse a esta experiencia de pérdida se hila en un montaje cinematográfico a medio camino entre recuerdo e imagen documental.

Para estudiar la experiencia en Benjamin es necesario hablar de dos términos que se distinguen y relacionan: Erlebnis y Erfahrung, en español han sido traducidos como vivencia y experiencia. Estos conceptos aluden a dos tipos de experiencia, una más 'pura' o sin intervención de la conciencia (Erlebnis) y otra más consciente y completa (Erfahrung). Si la experiencia de la vida moderna está constituida por el shock o su propia ruptura, para Benjamin ese registro ocurriría en forma de Erlebnis, una sensación que no llega a la consciencia, pero que puede ser reconstruida o rememorada como Erfahrung y en conjunto formar la experiencia vivida. Es decir, "[I]a rememoración complementa la «vivencia» [Erlebnis] [...] La reliquia procede del cadáver, rememoración de la experiencia [Erfahrung] ya difunta que, eufemísticamente, se llama vivencia [Erlebnis]" (Benjamin, 2008a, p. 290). Ambos conceptos para Benjamin (2008b) se distinguen y se complementan en la poesía de Baudelaire; aparece el shock como vivencia y al reconstruirse se convierte en experiencia poética. Así, acercarnos a la vida cotidiana es también cuestión de experiencia, "[p]ues allí donde impera la experiencia [Erfahrung] en su sentido estricto, ciertos contenidos que son propios de nuestro pasado individual entran finalmente en conjunción con los del colectivo en la memoria" (Benjamin, 2008b, p. 213).

Peter Osborne (1992) en su análisis sobre vanguardia y vida cotidiana se acerca a los escritos de Benjamin e identifica lo cotidiano como un elemento clave para la profundización en el concepto de experiencia; insiste que el objeto de estudio de Benjamin finalmente es "la construcción de la vida." Para Osborne el surrealismo y la teoría freudiana fueron importantes en el proyecto bejaminiano de pensar la vida cotidiana a través de la experiencia. Dichas teorías le ofrecían a Benjamin la

1 Frase con la que Benjamin inicia "Calle de Dirección Única", tal como Osborne señala. 
posibilidad de vincular lo cotidiano con lo extraordinario, el inconsciente y los sueños. Las propias descripciones que Benjamin hace de la ciudad y los pasajes están llenas de experiencias que evocan los sueños. El despertar o el paso del sueño a la vigilia para recordar lo soñado son metáforas y experiencias comunes en los escritos de Benjamin para hablar de la memoria. En el Libro de los pasajes, por ejemplo, Benjamin se refiere a la historia de la siguiente manera:

El nuevo método dialectico de la historiografía se presenta como el arte de experimentar el presente como el mundo de la vigilia al que en verdad se refiere ese sueño que llamamos pasado. iPasar por el pasado en el recuerdo del sueño! -Por tanto: recordar y despertar son íntimamente afines. Pues despertar es el giro dialéctico copernicano de la rememoración. (2005b, p. 394)

Este umbral entre dormir y estar despierto le interesa a Benjamin, un despertar donde todavía hay residuos de sueños, pero estos sueños son traídos al tiempo presente de la vigilia. De esta misma forma es que se podría construir la experiencia de la vida cotidiana donde los recuerdos siempre estarían interactuando con el presente, dando lugar a algo extraordinario. Así, los sueños y el despertar son como la vida cotidiana, pues ella nunca es captada únicamente como experiencia pura de la realidad (Erlebnis). En un sentido benjaminiano el estudio de la vida cotidiana no podría darse en la 'observación directa' sino en trabajos cuya estructura pueda albergar la construcción de dicha experiencia, como colecciones, diarios o a través de un lente cinematográfico que recopila escenas. Es decir, no habría una manera de acceder a la experiencia de la vida cotidiana como un fenómeno que no implique ya una reconstrucción.

Pero pensar la vida cotidiana a través de la experiencia, los sueños o lo extraordinario resulta problemático para algunos. Por ejemplo, para Henri Lefebvre (1991), la cotidianidad concebida como una experiencia surreal deformaría la vivencia cotidiana. Según Lefebvre la vida cotidiana estaría lejos de ser maravillosa, es decir, vincular lo cotidiano con lo extraordinario o surreal solo podría resultar en una forma de alienación. Lefebvre suscribe la noción marxista de alienación y es desde allí desde donde hace la mayoría de sus críticas de la vida cotidiana. Aunque Benjamin también hace lecturas marxistas en su trabajo, la concepción y las posibilidades de acercarse a la vida cotidiana de ambos pensadores difiere. En un sentido lefebvriano, la vida cotidiana sería una categoría más del capitalismo y la modernidad, por ello, la vida cotidiana ameritaría una crítica que dista de la experiencia como algo extraordinario.

\section{Totalidad agujereada}

En sus trabajos sobre la crítica de la vida cotidiana, Lefebvre (1991) se refiere a la concepción de lo cotidiano en función de la separación entre trabajo y ocio. Reflexiona históricamente acerca de división casa-trabajo y la considera un aspecto fundamental en el proceso de alienación en el que se convirtió la vida cotidiana. Lefebvre (1991) hace un recuento de escenas no muy distintas a Las espigadoras de Millet y expone, "en aquellas épocas, en esos modos de producción, el trabajo productivo estaba mezclado con la vida cotidiana [...] el espacio de trabajo está en la casa; el trabajo no está separado de la vida cotidiana de la familia" (Lefebvre, 1991, p. 30). Así, Lefebvre sostiene que con la sociedad burguesa vino la separación o la diferenciación entre ocio y trabajo, pero que, al mismo tiempo, se instituye la idea de que son complementarios. El trabajo era el valor principal para la sociedad burguesa, así que la individualización y especialización separada de la vida familiar o del ocio, se convirtió en la norma. Es decir que para Lefebvre (1991) la diversificación de las habilidades laborales fue lo que trajo la lógica del tiempo industrial y la necesidad del ocio o la relajación al terminar la jornada laboral.

En lugar de esta división alienante Lefebvre propone entonces la vida cotidiana como una totalidad. La vida cotidiana estaría relacionada con todo y representaría un todo que reconciliaría lo que la sociedad burguesa separó:

$[E]$ s en la vida cotidiana que la suma total de las relaciones que conforman lo humano - y a cada ser humano- toman la forma de un todo. En ella están expresadas y logradas esas relaciones que ponen en juego la totalidad de lo real, y en cierta forma también aquello que es siempre parcial e incompleto: amistad, camaradería, amor, la necesidad de comunicarse, el juego, etc. (Lefebvre, 1991, p. 97)

Sin embargo, si bien esta totalidad es entendida en su relación con todas las actividades, al mismo tiempo para Lefebvre, la vida cotidiana termina siendo una especie de purificación a través del análisis: "la vida cotidiana [...] definida por 'aquello que queda' luego de que cada actividad distinta, superior, especializada o estructurada ha sido sacado a través del análisis, debe 
ser definida como totalidad" (Lefebvre, 1991, p. 97). Parece sugerirse que la vida cotidiana 'debe' ser de una manera específica, una suerte de modelo pre-burgués - la totalidad de la vida antes de estar dividida entre trabajo y ocio.

El concepto de vida cotidiana de Lefebvre parece referirse a aquello que está relacionado con cada aspecto de la vida (total), pero también una vida que ha pasado por el tamiz de la crítica para ser analizada y despojada de las actividades especializadas (purificación). Para Guy Debord (1999) este modelo lefebvriano corre el riesgo de perder de vista la vida cotidiana misma. Debord explica que en el análisis de Lefebvre se pudieran identificar actividades especializadas en todos lados y nunca aparecer la vida cotidiana. Según Debord esta forma de concebir a la vida cotidiana hace de la 'gente común' un objeto de estudio del cual extraer la vida cotidiana originaria. En este sentido, es como si Lefebvre estuviese preocupado por encontrar la piedra fundacional del modelo cotidiano humano y este coincidiera con la vida campesina europea. La memoria campesina se convierte en cierta forma en un monumento. Pero Lefebvre (2013) no convoca abiertamente a que volvamos a otros tiempos, sino que sus reflexiones sobre la ciudad y el espacio llaman a la producción de algo nuevo que pueda registrar esa vida cotidiana no alienada por lo especializado y mecanizado. Pareciera, entonces, que propone algo nuevo que pueda 'purificar' la vida y como resultado obtener una cotidianidad no dividida en trabajo y familia (ocio), es decir, como la de antes.

La vida campesina de antes es tomada por Lefebvre como un hecho histórico o fáctico. Como si pudiésemos registrar lo que es la vida cotidiana a través de un método universal o bajo los modelos europeos conocidos. Es decir, la totalidad se convierte en un tiempo pasado específico y en un solo lugar: Europa. Así, la pregunta por la vida cotidiana y la posibilidad de acercarnos a ella también ha sido formulada desde otros continentes, aunque inevitablemente atravesada por la idea de la modernidad. Josefina Ludmer (2010) en su libro Aquí América Latina explora el entramado entre ciudad, memoria y vida cotidiana en Buenos Aires del año 2000. Su libro consiste en una especie de diario de lectura de ese año mientras divaga entre temas que terminan hilando diversos posibles órdenes de temporalidades locales, globales y la narración misma. Ludmer está interesada en una suerte de 'ficción temporal' y cómo algunas novelas presentan un tiempo histórico que dan un posible orden a la sociedad de un Buenos
Aires a las puertas del nuevo milenio. Pone en duda la noción del tiempo histórico a través de una especie de tiempo realidad-ficción que plantea como punto de partida. Así, otra división distinta a la de Lefebvre le parece crucial y es esa entre civilización y barbarie. Esta fórmula histórica, en un sentido casi canónico para Latinoamérica, marca un quiebre que supone una nueva posibilidad temporal en cada novela. Ludmer quiere romper con la solemnidad con que se ha tratado la historia y sugiere como método de lectura la 'agitación del tiempo', el descolocamiento de la continuidad aparente que ofrece la historia.

Quien pueda atreverse a mirar el paso del tiempo, para Ludmer, debe ser un agitador del tiempo, estar dispuesto a recorrer caminos menos certeros que los que ofrecen los libros de historia, "el tiempo del agitador no es puramente cuantitativo, lineal, homogéneo y orientado a un fin; es un tiempo con lagunas y agujeros, sin progreso ni desarrollo" (Ludmer, 2010, p. 118). Pero el tiempo que observa Ludmer no puede ser una totalidad, es un tiempo agujereado, incompleto y más cercano a la experiencia que Benjamin sugiere. El tiempo y el espacio no pueden estar simplemente definidos y delimitados. Si volvemos al documental y la pintura de Millet, vemos que Varda también está preocupada por el cambio entre un pasado y un presente en cierto contexto europeo, pero completamente afectado por las migraciones y las promesas de un mundo sin fronteras. Sin embargo, Varda no propone este cuadro como el ideal a seguir — como quizás sí lo haría Lefebvre-, sino más bien como un pretexto para hablar del paso del tiempo. Un tiempo que va a aparecer como algo colectivo - algo que se acerca a la idea de historia-y también como una experiencia en primera persona que va dejando arrugas en su propio cuerpo. El tiempo y su transcurrir, en todo caso, haría visible la pérdida de algo como una totalidad.

\section{Historia y el tiempo del ahora [Jetztzeit]}

En "Sobre el concepto de historia" Benjamin (2008c) propone que la historia es una herramienta poderosa y peligrosa al mismo tiempo, un artefacto de la sociedad que precisa una transformación. Para él las palabras 'historia' y 'pasado' son usadas indiscriminadamente por historiadores y cronistas, invisibilizando sus diferencias y subestimando la autoridad otorgada a la historia. Benjamin insiste en que la imagen del pasado que usan los cronistas está absolutamente intervenida por el concepto de historia tradicionalmente usado por los 
académicos e historiadores. Sin embargo, Benjamin se empeña en separar pasado de historia para insistir en que el pasado no es simplemente alcanzable, "[I]a verdadera imagen del pasado pasa súbitamente. El pasado solo cabe retenerlo como imagen que relampaguea de una vez para siempre en el instante de su cognoscibilidad" (Benjamin, 2008c, p. 307). De esta forma, si en el proceso de aproximarse al pasado no se reconoce el presente o no se muestra una dificultad en acceder a él la imagen del pasado es distorsionada, se hace estable una imagen que solamente puede estar relampagueando. La crítica de Benjamin es precisamente hacia una especie de totalidad de la historia que convierte al pasado en una memoria apropiada exclusivamente por las clases dominantes como una verdad incuestionable. Pero Benjamin no pierde la esperanza en el concepto de historia, más bien desea intervenir en una mejor escritura de la historia a través del materialismo histórico en contra del historicismo que toma los hechos como verdades.

Al Benjamin (2008c) escribir este ensayo, está cuestionando las leyes de la historia del siglo XIX donde los historiadores han escrito desde el lado de la victoria olvidándose, deliberadamente o no, de aquellos que han sufrido las consecuencias de la dominación. Cuando Benjamin reflexiona acerca de la historia, lo hace en el contexto del nazismo naciente y la Primera Guerra Mundial, por ello este escrito aparece como una advertencia de los peligros de la historia: "[n]o hay documento de cultura que no lo sea al tiempo de barbarie. Y como él mismo no está libre de barbarie, tampoco lo está el proceso de transmisión en el cual ha pasado desde el uno al otro" (Benjamin, 2008c, p. 309). Benjamin insiste en el riesgo de que la historia se enmarque en un espacio de injusticia y en consecuencia lleve al fascismo. Cuestiona la labor del historiador que trata de eliminarse a sí mismo - casi artificialmente- de lo que escribe, pues al hacer esto, cumple su labor en el nombre de la historia y por lo tanto en nombre de los vencedores.

Es en medio de la desilusión ante la guerra que Benjamin (2008c) escribe sobre el ángel de la historia que identifica en Angelus Novus, la pintura de Paul Klee (1920). Se trata de un ángel que mira hacia el pasado mientras la tormenta del progreso se desata y lo lleva inevitablemente al futuro que se encuentra a sus espaldas. El ángel no puede ver el futuro, que es a dónde la tormenta lo está llevando, y por ello se encuentra atrapado en el medio del enredo histórico, sin poder dejar de mirar al pasado. En esta escena la relación del pasado, presente y futuro existe, pero siempre enrevesadamente (Benjamin, 2008c). Así, Benjamin (2008c) advierte cómo la historia, hasta ahora, no ha logrado relacionarse con el presente (con quien la escribe y desde donde la escribe) y solo ocupa la función de ser una prueba fáctica y estable de épocas anteriores, es decir, otra mercancía de la modernidad. Aquí es clave la diferencia entre el pensamiento de Benjamin y el de Lefebvre, pues para Lefebvre la mercancía de la modernidad sería la división entre trabajo y ocio; los hechos históricos son la prueba de que alguna vez no existió dicha división.

Si el tiempo del historiador clásico o el tiempo histórico es un tiempo vacío y homogéneo, Benjamin (2008c) propone el 'tiempo del ahora' o el Jetztzeit como el tiempo del materialista histórico. El tiempo del ahora transformaría la historia como la conocemos para narrar crónicas históricas que puedan evocar la vida cotidiana de una determinada época en el presente. Desde la lectura de McCraken (2002), Benjamin ofrece la posibilidad de llenar el tiempo histórico de tiempo del ahora, y esto sería algo transformador, "[...] el efecto es el de distanciarse, un verdadero Verfremdungseffekt [extrañamiento] bretchiano, donde la 'naturalidad' de lo que 'en realidad pasó' es des-familiarizada y puesta a la orden de la crítica y práctica política" (McCraken, 2002, p. 163). El tiempo del ahora es el tiempo donde Benjamin encuentra la posibilidad de rescatar el concepto de historia, una historia que le hiciera justicia a la vida cotidiana. Pero en Benjamin no solo aparece la sugerencia de llenar la historia de Jetztzeit, sino también un despliegue de esta forma histórica en la escritura. En el Libro de los pasajes (Benjamin, 2005a) vemos una colección de pequeños ensayos, descripciones de objetos, lugares e impresiones; un compilado laborioso que reflejaría una constelación temporal compleja y no un tiempo anterior total o estable.

\section{Ritmos e instantes}

Volvamos por un instante a la escena que Lefebvre (1991) propone de la vida campesina, donde el trabajo estaba unido a la familia y año tras año la familia espigaba el producto de la cosecha, tal como narran los personajes del documental de Varda acerca de sus ancestros. Allí, en estas escenas del siglo XIX, la vida cotidiana tenía su propia temporalidad: la repetición. Lefebvre afirma que la temporalidad de la cotidianidad, incluso ahora, es indudablemente la repetición: 
Lo cotidiano está situado en la intersección de dos modos de repetición: la cíclica, que predomina en la naturaleza, y la lineal, que predomina en los procesos conocidos como 'racionales.' Lo cotidiano implica por un lado ciclos, días y noches, temporadas y cosechas, actividad y descanso, hambre y satisfacción, deseo y satisfacción, vida y muerte y por otro lado implica los gestos repetitivos de trabajo y consumo. En la vida moderna, los gestos repetitivos tienden a enmascarar y destruir los ciclos. (Lefebvre, 1987, p. 10)

Para Lefebvre el efecto de la modernidad siempre es el de destruir los ciclos "naturales" de la vida cotidiana. Como si los ciclos no pudieran existir fuera del escenario ideal del antiguo campo europeo donde Lefebvre se empeña en encontrar el origen de la vida cotidiana. El argumento científico-social de Lefebvre funciona para fijar históricamente la vida cotidiana como un ideal desafortunadamente perdido. En el documental de Varda vemos la repetición de la cosecha, los días que transcurren en la espera de la siembra, pero también vemos la periodicidad del consumo, las sobras, la basura e incluso lo que se descompone dentro y fuera de los comercios. Los supermercados estipulan una fecha de caducidad de la comida, tratando de establecer algún orden en la dinámica de descomposición anticipando el cambio biológico. En Varda también hay una crítica implícita a esa dinámica de consumo que contrasta con lo natural. Pero ella no puede simplemente defender 'lo natural' o una vida cotidiana 'pura', como si realmente pudiera tener acceso a ella. El lente cinematográfico y la propia presencia de Varda en el documental funcionan precisamente como una complicación de capas ante cierto ritmo, interrumpido y fluido al mismo tiempo, que está tratando de registrar y que no se deja atrapar sino solo fugazmente, como quizás diría Benjamin.

La labor de la modernidad es el enmascaramiento del ciclo natural, nos dice Lefebvre (1987), el menor cambio está programado o anticipado. En este sentido, Osborne (1992) también habla de la monotonía de la vida cotidiana que en la modernidad trata de imponerse y esto se traduce en la naturalización del 'todo es siempre lo mismo', o lo que Benjamin llamaría historicismo. Para Osborne, la lógica de la monotonía traería un aplanamiento que terminaría negando la posibilidad de un verdadero tiempo histórico lleno de tiempo del ahora. Rescatar la historia de esta monotonía, si seguimos a Benjamin y Osborne, solo pudiera darse en la refiguración de la vida cotidiana. Tal como Osborne leyendo a Benjamin propone, "la negación del tiempo histórico por la lógica de la repetición podría revertirse a través de la transformación de la cronología vacía del 'instante' en la llenura del 'ahora' histórico" (Osborne, 1992, p. 196). Ante el 'todo es siempre lo mismo' o 'todo está predicho' como amenaza de la construcción de la vida cotidiana y la historia, entran en juego el instante y el ahora. Un instante y un ahora de la vida cotidiana que podrían aparecer, aunque fugaz y sorpresivamente, como experiencia.

En todos los escritos que hemos analizado hasta ahora hay una crítica o una incomodidad con la uniformización que trae la modernidad y lo complicado que se hace acceder a algo como la vida cotidiana. Sin embargo, para Benjamin el problema no estaría en volver a un determinado momento de la vida cotidiana real — donde familia y trabajo no estuviesen separadas, como diría Lefebvre - sino en un trabajo crítico a la historia que se cree capaz de hablar en nombre de la cotidianidad. La modernidad, al dejar ver lo fallido de su proyecto o al enfrentarnos al shock de la pérdida, nos muestra también la imposibilidad de un acceso directo (o un tiempo progresivo que nos lleve) a la vida cotidiana. Es en la experiencia donde fugazmente puede recogerse algo de vida cotidiana y de ahí reconfigurar la escritura de la historia.

\section{Espigando el tiempo: rejuvenecimiento de las memorias}

En su ensayo Perspectivas de la modificación consciente de la vida cotidiana, Debord formula lo siguiente: "(I)a vida cotidiana presenta efectivamente hasta nuestros días resistencia a lo histórico" (1999, p. 189). En esta afirmación y en su ensayo nos insinúa que la heterogeneidad de la vida cotidiana no ha podido ser atrapada por algún proyecto histórico o que es desde lo cotidiano que se podría resistir el historicismo homogeneizador. Debord escribe "La historia —es decir, la transformación de lo real- no puede utilizarse actualmente en la vida cotidiana porque el hombre de la vida cotidiana es el producto de una historia sobre la que no tiene control. Es evidentemente él mismo quien hace esta historia, pero no libremente" (1999, pp. 189-190). El rol que ha tenido la historia a lo largo de los años según Debord coincide con la denuncia de Benjamin de una historia llena de tiempo vacío e instrumento infalible de la clase dominante. Si embargo, Debord parece aún confiar en una realidad que la historia ha deformado y a lo cual podríamos acceder si logramos 
contrarrestar el efecto de la historia o a través de la vida cotidiana misma.

Así, Benjamin persigue una crítica de la vida cotidiana y de la historia desde la experiencia porque esta no puede aspirar un acceso total a 'la historia real' o a 'la vida cotidiana real'. La apuesta por la historia aparecería en la medida en que una re-figuración de la vida cotidiana, en tanto experiencia, fuese posible. En relación con esto Osborne nos dice que la vida cotidiana en Benjamin es una constante "de-historización incompleta" y por lo tanto es un campo fértil para la "re-historización de la experiencia" (1992, p. 196); tal como podemos leer en el texto de Benjamin:

El historicismo se contenta con establecer un nexo causal entre momentos diferentes de la historia. Mas ningún hecho es, en cuanto causa, justamente por eso ya histórico. Se ha convertido en tal, póstumamente, con empleo de datos que pudieran hallarse separados de él por milenios. El historiador que parte de ello deja de permitir que una mera sucesión de datos corra por los dedos al igual que un rosario. Con ello, capta la constelación en que se adentró su propia época junto a una anterior que se halla determinada totalmente. Funda así un concepto de presente como el «tiempo-ahora», ése en el cual se han esparcido astillas del mesiánico. (Benjamin, 2008c, p. 318)

Benjamin apuesta por una rehabilitación de la labor del historiador (o el materialista histórico) que trataría la historia como una red compleja de relaciones donde estaría incluida también su propia figura. Solo en la medida en la que el historiador lograra identificarse dentro de esta red de relaciones que conforma la historia podría construirse una historia llena del tiempo del ahora; una historia menos vacía y menos solemne. No es casualidad entonces que Benjamin relacione la labor de escribir la historia con la de coleccionar en su trabajo sobre "Eduard Fuchs coleccionista e historiador". También en su Libro de los pasajes, Benjamin estructura un gran proyecto entre la vida cotidiana y la historia; una colección de descripciones de objetos, imágenes poéticas, ensayos y otros. En el siguiente fragmento Benjamin describe al coleccionista, pero también podemos escuchar un eco de lo que aspira para el historiador:

Pero eso es lo que le ocurre al gran coleccionista con las cosas. Le asaltan de improviso. El hecho de perseguirlas y dar con ellas, el cambio que opera en todas las piezas una pieza nueva que aparece: todo ello le muestra sus cosas en perpetuo oleaje [...]. En el fondo se puede decir que el coleccionista vive un fragmento de vida onírica. (Benjamin, 2005a, p. 224)

Para Benjamin la colección está llena de experiencia, de sorpresa, reconstrucción y tiempo, un tiempo que no puede ser simplemente homogéneo, real o fáctico. Coleccionar o reconstruir ameritaría poder estar en un 'perpetuo oleaje', sin poder 'cerrar' la colección (o la historia) antes de que pueda seguirse buscando. Varda en su documental se hace una espigadora o una coleccionista. El 'espigado' le permite sorprenderse de lo inesperado, y es en el encontrar y sorprenderse que va a estructurar la narrativa de lo que cuenta. Así, Varda presenta obras de arte sin tratar de hablar en nombre de La Historia del Arte, nos cuenta la vida de personas que viven al margen evitando el lenguaje sociológico comúnmente usado al referirse a las minorías, y así, estas secuencias cinematográficas construyen una amplia red acerca de la cotidianidad de espigar. Pero este entretejiendo que sostiene el montaje de su filme no ocurre a expensas de monumentalizar la vida cotidiana, ni en un tiempo vacío; más bien va hilándose entre memorias, ciclos y procesos de envejecimiento.

Podríamos decir que la imagen que construye Varda en Los espigadores y la espigadora, es cercana al interés que tenía Benjamin de entender el tiempo de la vida cotidiana como un despertar. Varda produce una suerte de experimentar el presente y el pasado como la reconstrucción de un sueño que ha dejado una impresión (Erlebnis y Erfahrung), una imagen onírica pero no por esto surreal. La manera en que Varda construye su montaje es parte del argumento mismo del filme: recoger algo que relumbre - puede ser una pintura clásica o una papa en forma de corazón-y (re)construir una constelación que la relacione a ella con este objeto. Un viaje o un recorrido de recuerdos que admite lagunas y discontinuidades. Así, Varda logra jugar con la idea del tiempo que va transcurriendo en tensión con Las espigadoras del Siglo XIX y también con su propio proceso de envejecimiento. Varda muestra sus manos al lente mientras su cuerpo y la profundidad de las arrugas aparecen como una marca indeleble del paso del tiempo (Imagen 3 y 4). Un tiempo de la vida cotidiana que no necesariamente es progresivo o uniforme y que, aunque puede desgastarlo todo, también arruina la idea misma de totalidad. Es el extravío de esa aureola baudeleriana que desafía la totalidad a que aspira Lefebvre. 

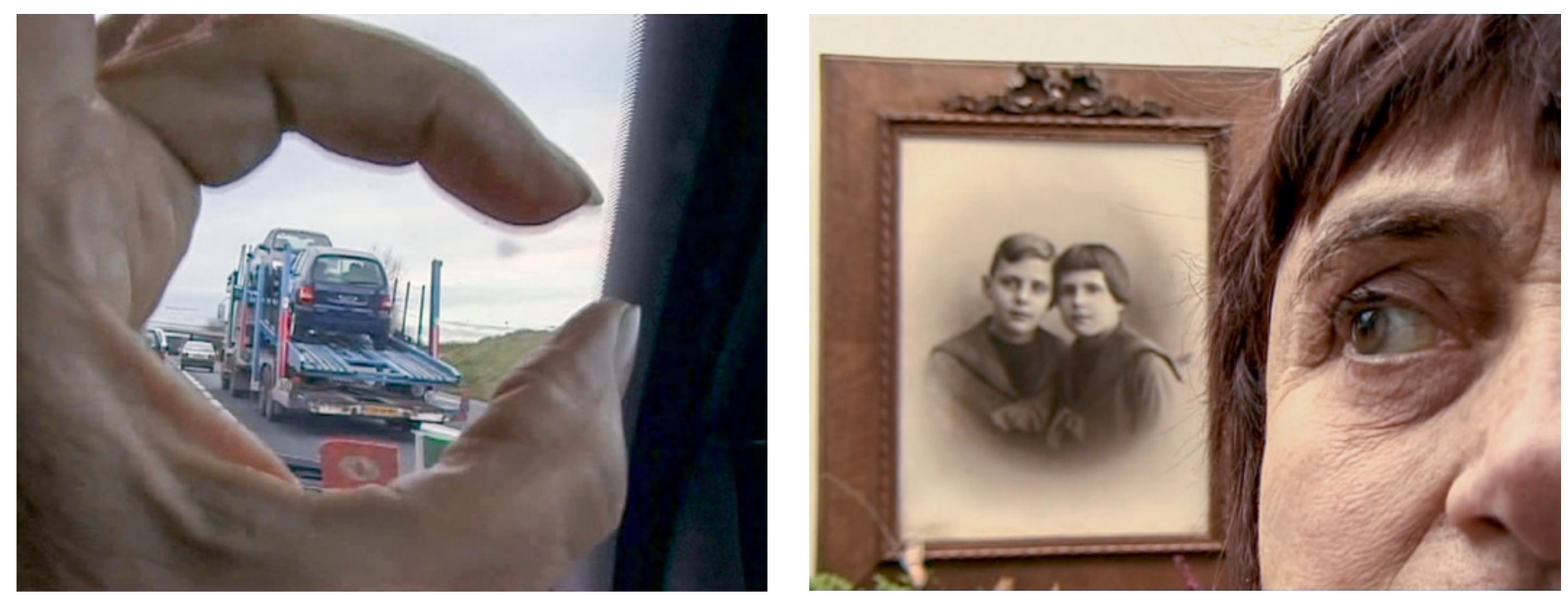

Imágenes 3 y 4. Les glaneurs et la glaneuse, Agnès Varda (2000). Cortesía: Film Grab.

Esta insistencia en el paso del tiempo recuerda el escrito de Benjamin (2007) sobre Marcel Proust, el recuerdo y la memoria. Benjamin expone que en la obra de Proust "lo más importante para el autor que recuerda no es lo que ha vivido, sino el proceso mismo en que su recuerdo se teje" (2007, p. 317). El proceso de rememorar y el recuerdo aparecen también como experiencia misma siendo el recuerdo mucho más amplio que la vivencia pues implica la constelación desde la que se rememora. Pero el recuerdo en Proust está envuelto completamente en el paso del tiempo, el envejecimiento, el desgaste físico exterior, tal como las manos de Varda. Según Benjamin, la complicación de Proust está en el envejecer y rejuvenecer al mismo tiempo:

Proust ha llevado a cabo la enormidad descomunal de hacer envejecer en un instante al mundo entero el espacio de una vida. Esta peculiar concentración en la cual eso mismo que se va marchitando se va consumiendo rápidamente, es, de repente, rejuvenecimiento. Porque À la recherche du temps perdu representa el intento inacabable de cargar una vida con la mayor presencia posible de espíritu. (Benjamin, 2007, p. 327)

Podríamos decir que en cierta forma la posibilidad de espigar, tal como la plantea Varda en un espíritu prousteano, tendría que ver con espigar el tiempo y en ese mismo movimiento rejuvenecer el recuerdo, es decir, otorgarle la vitalidad de sus conexiones. Así, también la versión temporal de Ludmer de la agitación del tiempo como una especie de fórmula de lectura resuena en las propuestas visuales de Varda. Ludmer propone que una agitadora del tiempo "puede deslocalizarse y moverse entre puntos temporales diferentes ( $y$ a velocidades y ritmos diferentes) [...] inventa el presente, concibe temporalidades alternativas, hace acordes con distintos pasados, imagina posibilidades (de otros tiempos y de otros sentidos del tiempo)" (2010, p.118). Esta agitadora (Ludmer, Varda o Benjamin) observa el tiempo como un concepto que le permite aproximarse al presente $\mathrm{o}$ al pasado a través de lagunas y no por medio de secuencias lineales que estructuran el tiempo como algo progresivo. Ofrece una propuesta que se abre a una lectura menos taxativa del pasado.

Aunque Varda no es historiadora o teórica, su perspectiva acerca del oficio de espigar, está cerca de lo que Benjamin esperaba para la reconstrucción de la vida cotidiana o lo que Ludmer insiste como agitación del tiempo. No es casualidad que el tiempo aparece como preocupación en muchas de sus películas. En Cleo de 5 a 7 (1961), un filme de ficción, Varda explora la complicación de la espera de resultados médicos que le permitirían saber a la protagonista si estaría condenada a morir de una enfermedad. Varda pone sobre la mesa la doble espera, la espera de los resultados agudizada en un momento (el de la película) y la espera de la muerte en la que parecemos estar sumidos siempre. Este tiempo alargado o comprimido es también el tiempo del cine y el montaje. Introducir el tema del tiempo en un documental, entonces, es llevar la problemática del tiempo más allá de la ficción y colocarlo en la posibilidad misma de narrar una historia o hacer un montaje.

Varda cierra la película tomando un objeto descartado por otro espigador, un reloj sin agujas (Imagen 5), y dice "me gusta esto porque no vemos el tiempo pasar" 


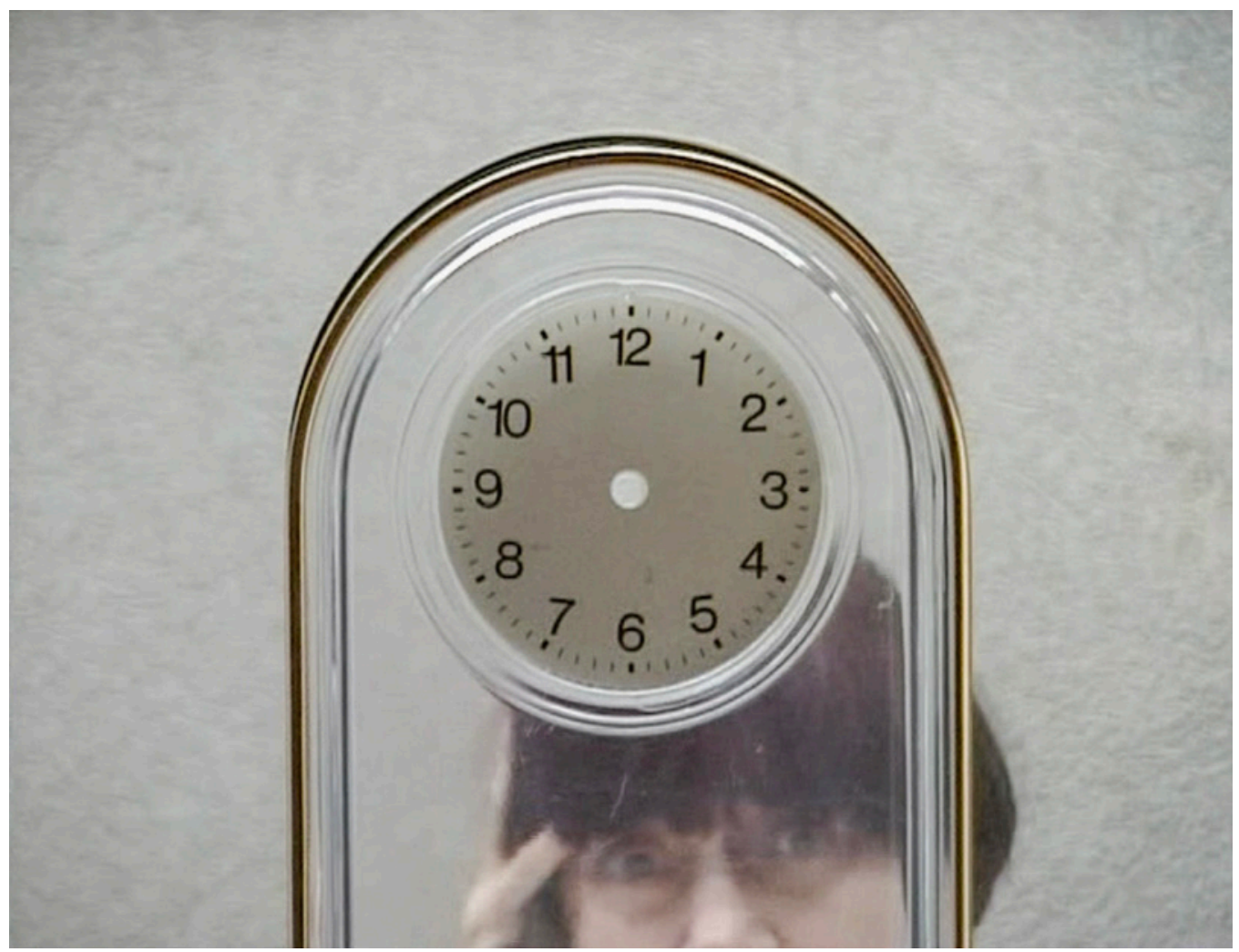

Imagen 5. Les glaneurs et la glaneuse, Agnès Varda (2000). Cortesía: Film Grab.

(2000). El tiempo también puede ser imperceptible y por eso amerita siempre una reconstrucción que pueda dar cuenta de las agujas que no se mueven. Así, a través del cambio en el oficio de espigar, Varda hace una metáfora del transcurrir de las horas, días, años, rutinas, cosechas. Espigar entonces es acerca del tiempo, de esperar, esperar por ese momento en el que la experiencia pueda aparecer. En una entrevista hecha a la directora, Varda acota lo siguiente:

El problema del tiempo, que es un problema del cineasta, lo exploré en Cleo y otras películas. En Los espigadores, recogí un reloj sin agujas. Y pregunté: "¿El tiempo pasa cuando no hay agujas?" iLa respuesta es sí! El tiempo pasa igual, pero las agujas no giran. Esta cuestión de tiempo siempre me ha fascinado. Tal vez sea un problema de todos, en todo caso de todos los artistas. (Varda, 2014, párr. 26)

El arte, entonces, puede dejar ver su propia artificialidad haciendo del tiempo (cinematográfico en este caso) un problema, una complicación. Espigar como una mera referencia histórica de los campesinos franceses sería reducir la palabra y su significado a una práctica obsoleta que Varda quiere revitalizar y rememorar con toda la constelación que eso implica. Como una coleccionista, Varda rescata el término y lo coloca en el medio de la vida cotidiana. Intenta a través de su imagen agitar el tiempo o de-historizar la palabra espigar. Al espigar, entonces, la vida cotidiana difícilmente puede verse como 'hechos reales' más bien se transforma en un acontecer de la búsqueda de la experiencia. Esta versión de la vida cotidiana ocurre en un tiempo que no está vacío, un tiempo capaz de registrar las arrugas del cuerpo y revitalizarlas en su recuerdo.

\section{Referencias}

Baudelaire, Ch. (2014 [1869]) "Extravío de aureola", en Esplín de Paris (Pequeños poemas en prosa), Madrid: Alianza Editorial.

Benjamin, W. (2005a [1982]). "[El coleccionista]" H, en Libro de los Pasajes, Madrid: Editorial Akal.

\section{(2005b [1982]). “[Ciudad y arquitectura}

oníricas, ensoñaciones utópicas, nihilismo antropológico, Jung]" K, en Libro de los Pasajes, Madrid: Editorial Akal. 


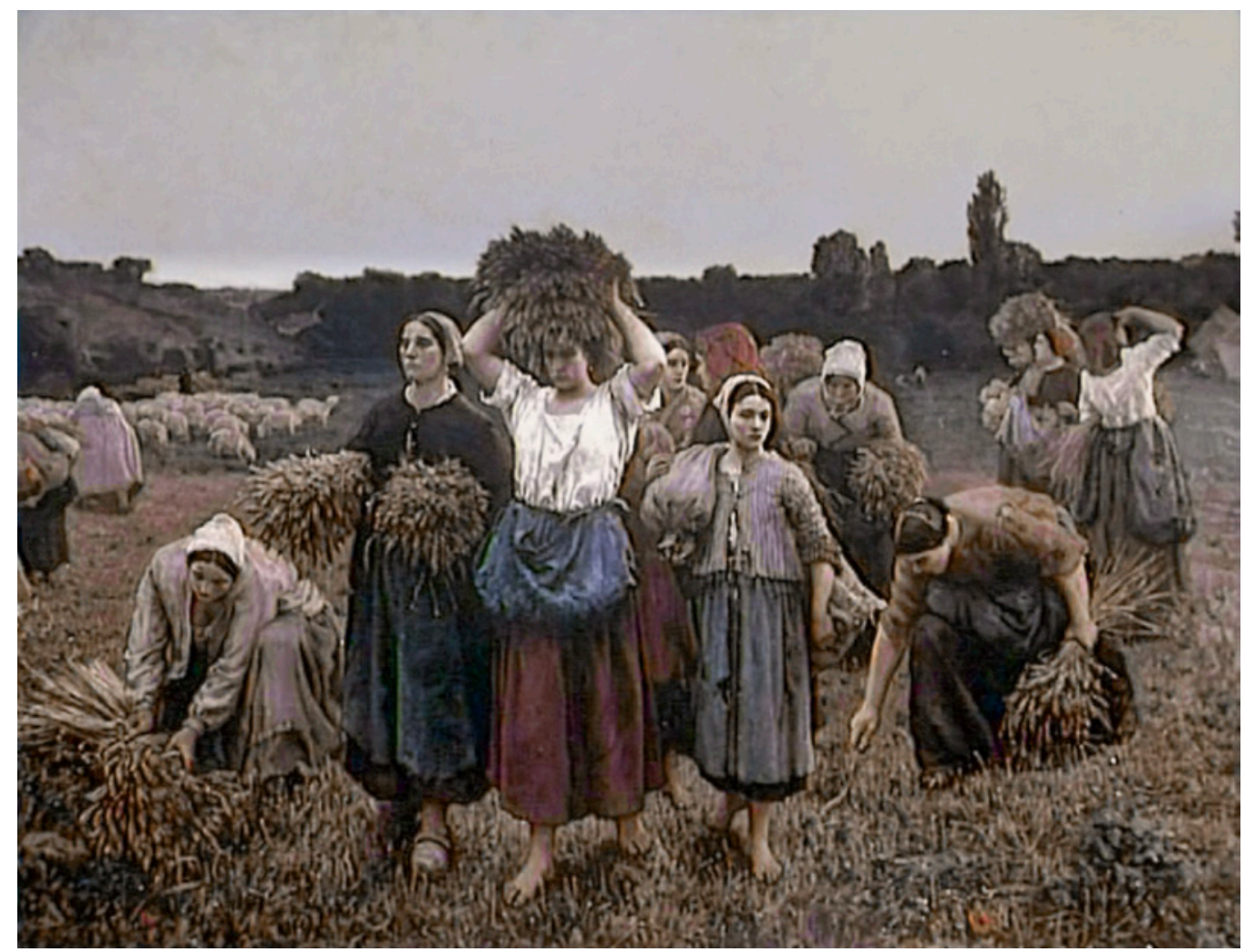

Imagen 6. Les glaneurs et la glaneuse, Agnès Varda (2000). Cortesía: Film Grab.

(2007 [1929]). “Hacia una imagen de

Proust", en Obras libro II/Vol. 1, Madrid: Abada Editores.

. (2008a [1938]). "Parque Central", en Obras

libro I/Vol. 2, Madrid: Abada Editores.

(2008b [1939]). "Sobre algunos motivos

en Baudelaire", en Obras libro I/Vol. 2, Madrid: Abada Editores.

(2008c [1940]). "Sobre el concepto de Historia", en Obras libro I/Vol. 2, Madrid: Abada Editores.

Debord, G. (1999). “Perspectivas de modificación consciente de la vida cotidiana", en Internacional situacionista: textos completos en castellano de la revista Internationale Situationniste (1958-1969), Madrid: Literatura Gris.

Lefebvre, H. (1987). "The Everyday and Everydayness", en French Studies, 73. https://doi.org/10.2307/2930193 (1991). Critique of Everyday Life: Volume I,
(2013 [1974]). La producción del espacio,

Madrid: Capitán Swing.

Ludmer, J. (2010). Aquí América Latina, Buenos Aires: Eterna Cadencia.

McCracken, S. (2002). "The Completion of Old Work: Walter Benjamin and the Everyday", en Cultural Critique, 52. https://doi.org/10.1353/cul.2003.0013

Osborne, P. (1992), "Avant-Garde and Everyday", en The politics of Time: Modernity and Avant-Garde, London: Verso.

Varda, A., y Maille, N. (2014). "Conversation aven Agnès Varda: les puzzles d'Agnès". Critkat. Doi: https://tinyurl.com/yyz8g62t

Varda, A. (1962) Clèo de 5 à 7, 35mm, 90'. (2000). Les Glaneurs et la Glaneuse, $35 \mathrm{~mm}, 82^{\prime}$.

London: Verso. 